\title{
Secondhand smoke exposure from the indoor and outdoor shisha centers located at the perimeter of educational institutions in Malaysia: a cross-sectional study
}

\author{
Suresh Kandagal Veerabhdrappa ${ }^{1}$ (D) Seema Yadav ${ }^{1}$. \\ Srinivas Sulugodu Ramachandra ${ }^{2}$ (D) . Daniel Devaprakash Dicksit ${ }^{1}$. \\ Khairiyah Bt Abd Muttalib ${ }^{1}$. Ahmad Termizi Bin Zamzuri ${ }^{1}$
}

Accepted: 3 December 2021 / Published online: 21 January 2022

(c) The Author(s), under exclusive licence to Springer Nature Limited 2021

\begin{abstract}
Shisha is a centuries-old traditional smoking habit rapidly gaining popularity among the students and young adults in Malaysia. The present study evaluated secondhand smoke exposure (SHS) and characteristics of 25 indoor and 25 outdoor shisha centers (SC) operating around the educational institutes such as universities in Petaling Jaya, Malaysia. We observed a significantly higher particulate matter $(\mathrm{PM})_{2.5}$ concentration in indoor than outdoor SC $\left(3595.28 \mu \mathrm{g} / \mathrm{m}^{3}\right.$ and $65.12 \mu \mathrm{g} /$ $\mathrm{m}^{3}, p<0.001$, respectively). SCs are offering different flavors to attract clients and exposing students and young professionals to a significantly high concentration of SHS. Such exposures may pose a serious health risk. Therefore, policymakers need to strengthen tobacco guidelines and eliminate loopholes in the sale of shisha by enforcing comprehensive and strict smoke-free laws.
\end{abstract}

Keywords Educational institutes $\cdot$ Policy $\cdot$ Secondhand smoke $\cdot$ Shisha smoking · Tobacco $\cdot$ Malaysia

\section{Introduction}

Shisha smoking is a global public health problem that has existed for centuries in the Middle East and northwestern provinces of India and has spread to the western world and southeast Asian countries [1]. Shisha smoking typically involves the inhalation of smoke from the burning tobacco and charcoal after it passes through the water [2]. The data from the recent studies unveiled the reduced tendency of cigarette smoking in public places due to enforcement of strict laws, and consequent increase in the use of alternate tobacco products such as shisha [2, 3]. Shisha

Suresh Kandagal Veerabhdrappa dr.suri88@gmail.com

Extended author information available on the last page of the article 
currently ranks as the second most consumed alternate tobacco product [4-6]. The prevalence of shisha smoking among youth ranges from 12.9 to $65.3 \%$ in the Eastern Mediterranean, 3-44\% in North America, 12.0-49.5\% in Europe [7], and 23.8\% in Hong Kong university students [8]. In Malaysia, its prevalence among university students was reported to be $30 \%$ [9] and $20 \%$ among medical students [10].

SHS from shisha consists of a mixture of poisonous gases such as carbon monoxide, polycyclic aromatic hydrocarbons, aromatic amines, tar, heavy metals, and fine particles that have been exhaled, or breathed out by the shisha smoker $[11,12]$. SHS also contains 39 central nervous system depressants, 31 respiratory irritants, and many other carcinogens that pose serious consequences for health [2, 12, 13]. In children, SHS can lead to the development of ear infections, asthma, and respiratory infections including fatal sudden infant death syndrome; in adults, it is linked to an increased risk of cardiovascular diseases and lung cancers [2]. Household SHS exposure was associated with a significant decline in global cognitive function, visuospatial ability, and memory function among Chinese women [14].

SC operators sell wide variety of flavors to attract young adults [1]. Additionally, shisha is being shared in groups; thus, it is more affordable than cigarette smoking [15] and is socially acceptable [5]. Shisha smoking sessions are longer than the cigarette smoking and allows smokers to perform various smoke tricks [15].Sale of shisha has fewer restrictions, and the lack of knowledge about on its harmful effects has resulted in young adults practicing shisha as an alternative to cigarette smoking [10]. A gradual surge in the number of SC that target students and young adults around the educational institutes and Universities may affect the surrounding air quality.

The SHS from shisha has considerable health consequences for nonsmokers, bystanders, and staff including increased uptake of nicotine, nitrosamines, and risk of exposure to carcinogenic and inflammatory biomarkers [16]. Researchers have reported the mushrooming of SC around the education institutions and Universities in Petaling Jaya, Malaysia [4, 6] that target young adults and students as their clients. There is a paucity of information in the literature about the air quality around these SC. Hence, this study aimed to measure the indoor and outdoor $\mathrm{PM}_{2.5}$ concentration as a marker for SHS and to evaluate the characteristics of these SC.

\section{Methods}

\section{Study design}

We conducted the cross-sectional study from November 2018 to January 2020 at 25 indoor and 25 outdoor SC located close to education institutions and Universities in Petaling Jaya, Malaysia. A summary of the study design and flow chart is appeared in Fig. 1. The study team chose SC using google maps, business directories, and social media using the search terms "shisha centers; shisha lounges; shisha bars; hookah bars; hookah lounges" and "colleges and universities" and "Petaling Jaya." Based on the search results, we selected SC through a simple random sampling method. The institutional ethical committee approved the study (SEGIIRF/2018-68) 
before the start. We did not seek consent from the SC to measure SHS as we measured only air quality.

\section{Calibration of the instrument and training of the observers}

We used the DustTrak ${ }^{\mathrm{TM}}$ II handheld aerosol monitor 8532 (TSI Incorporated, Shoreview, $\mathrm{MN}$ ) to measure the $\mathrm{PM}_{2.5}$ concentration. The instrument was calibrated according to the manufacturer's specifications before recording measurements. Two researchers (KVS and DDS) visited the SC as clients and made measurements covertly to ensure that the presence of the researcher did not alter the smoking behavior of the patrons. One researcher (KVS) whom we trained to collect the data from the instrument recorded the $\mathrm{PM}_{2.5}$ concentration in all the SC; DDS recorded the characteristics of each SC with the demographic details. After assessing the previously published literature and the following discussion among researchers (KVS, DDS), the research team finalized an assessment checklist to use when recording the observations at the SC. We adapted this checklist from a previous study [6].

\section{Measurement of SHS from SC}

The researchers placed the aerosol monitor in a handbag with a tube extended outside of the bag to sample the air (Fig. 2). The researchers made measurements during evenings from 8 to $11 \mathrm{pm}$ on Friday, Saturday, and Sunday as most SC operates in the evening, and late into the night on weekends. We classified SC with

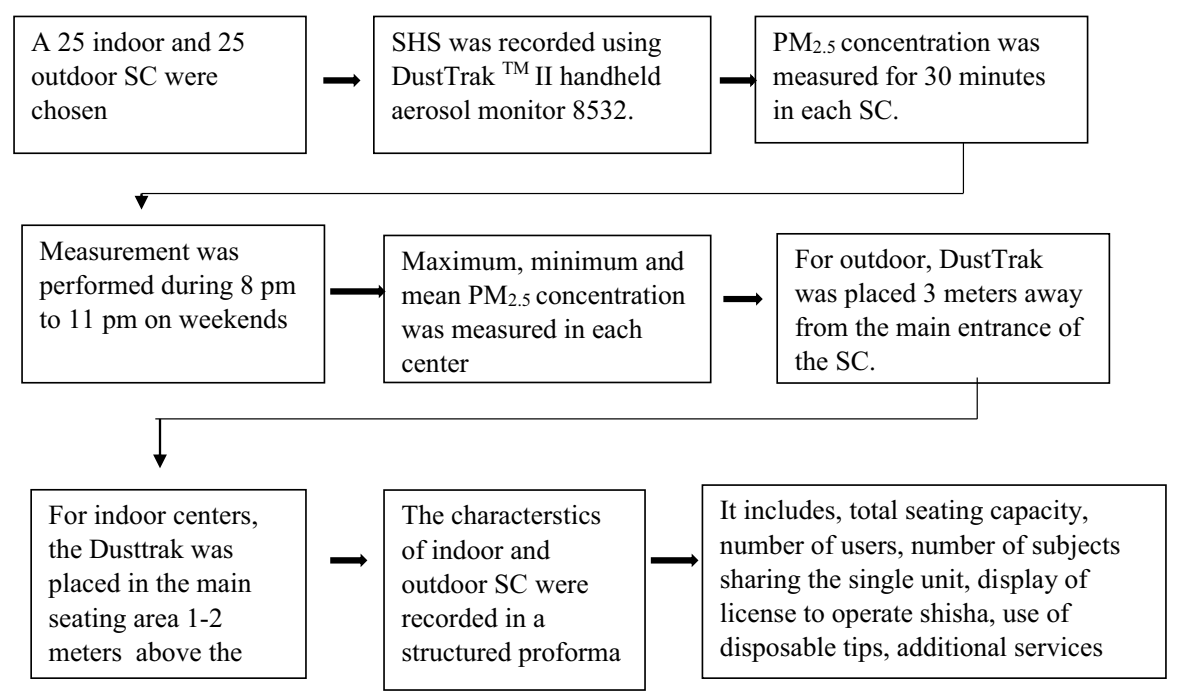

Fig. 1 Flowchart of the study design 
ventilation sources such as open doors or windows without air conditioners as "outdoor centers," and those with air conditioners and closed doors as "indoor centers."

\section{Statistical analysis}

We downloaded the data from the aerosol monitor following each visit using the TSI Trackpro V3.4.1 software and analyzed these data using Statistical Package for the Social Sciences Statistics for Windows version 22 (IBM Corp.: Armonk, New York, The United States). We tested the normality of the data using the Shapiro Wilk test and Quantile-Quantile generated plots to determine the normality of the data. As the data followed a non-normal distribution, we used the Mann-Whitney test. We analyzed the characteristics of SC using an unpaired t test and chi-square test.

\section{Results}

\section{Secondhand smoke from indoor and outdoor SC}

The mean, minimum, and maximum $\mathrm{PM}_{2.5}$ concentration in indoor $\mathrm{SC}$ were $3595.28 \mu \mathrm{g} / \mathrm{m}^{3}, 30 \mu \mathrm{g} / \mathrm{m}^{3}$, and $19,000 \mu \mathrm{g} / \mathrm{m}^{3}$, respectively, while the mean, minimum, and maximum $\mathrm{PM}_{2.5}$ concentration in outdoor $\mathrm{SC}$ were $65.12 \mu \mathrm{g} / \mathrm{m}^{3}, 27 \mu \mathrm{g} /$ $\mathrm{m}^{3}$, and $148 \mu \mathrm{g} / \mathrm{m}^{3}$, respectively. We found a significantly higher $\mathrm{PM}_{2.5}$ concentration in indoor SC as compared to outdoor SC (Table 1). The mean $\mathrm{PM}_{2.5}$ concentration in indoor SC was 50 times greater than the concentration in outdoor SC. The minimum, maximum, and mean $\mathrm{PM}_{2.5}$ concentration were statistically significant in indoor than outdoor SC with the $p=0.010(U=179),<0.001(U=51)$, and $<0.001(U=102)$, respectively (Table 1$)$.

Fig. 2 Measurement of $\mathrm{PM}_{2.5}$ concentration using DustTrak TM II aerosol monitor 8532 with the tube extended outside of the bag to draw the air sample

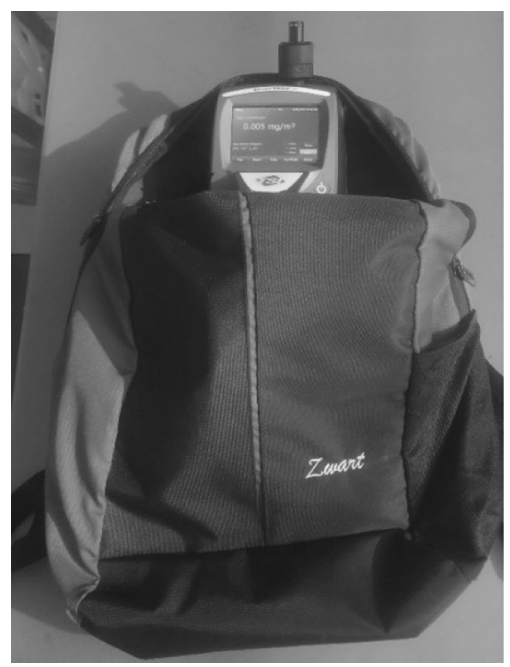




\section{Characteristics of indoor and outdoor SC}

We observed active shisha smoking in all the centers at the time of data collection (Table 2). The average seating capacity was $21.44 \pm 3.85$ and $26.36 \pm 7.15$ for indoor and outdoor SC, respectively. The outdoor SC had a slightly higher number of seats than indoor SC $(p<0.004)$. The average number of active shisha users was $14.28 \pm 4.31$ and $15.68 \pm 6.46$ for indoor and outdoor SC $(p=0.372)$, and we observed an equal number of shisha units being used in both types of centers $(p=0.851)$. We noticed that most of the users in indoor $(76 \%)$ and outdoor (80\%) SC were sharing the single unit of shisha with others and only half of the (56\%) of indoor SC provided disposable mouthpieces, compared to $88 \%$ of outdoor SC; this was statistically significant $(p=0.013)$. About $80 \%$ of indoor and $72 \%$ of outdoor SC provided additional services such as food, drinks, and free Wi-Fi services in addition to the shisha units. Display of a license to operate shisha and display of smoking hazard sign were absent in most of the SC. More than half (56\%) of the indoor and outdoor SC advertised shisha units and displayed banners with promotions at the entrance of the SC (Table 2).

\section{Discussion}

Shisha smoking has become an epidemic in the last two decades, particularly among young adults, professionals, and University students [17]. This could be attributed to a false perception of shisha being safe and to a newer marketing strategy featuring fruity flavoring agents $[18,19]$. The concentration of PM in the air is a strong indicator of pollution and to evaluate the air quality [17]. Dusttrak ${ }^{\mathrm{TM}}$ II Aerosol Monitor 8532 is a battery-operated, light-scattering laser photometer that provides real-time PM concentration ranging from 0.1 to $10 \mu \mathrm{m}$ and is ideal to measure the SHS [17]. The present study evaluated the indoor and outdoor SHS from SC operating around the educational institutions and Universities. We found significantly higher mean indoor $\mathrm{PM}_{2.5}$ concentration of $3595.28 \mu \mathrm{g} / \mathrm{m}^{3}$ in $\mathrm{SC}$, and these findings were greater than the measurements recorded in the United States and Canada [20-22]. Various researchers reported mean $\mathrm{PM}_{2.5}$ concentration as presented in Table 3 [17, 20-24].

Table 1 Descriptive Statistics of the $\mathrm{PM}_{2.5}$ concentration observed in 25 Indoor and 25 outdoor SC

\begin{tabular}{llrccc}
\hline $\begin{array}{l}\mathrm{PM}_{2.5} \text { concentration } \\
\left(\mu \mathrm{g} / \mathrm{m}^{3}\right)\end{array}$ & Mean & $\begin{array}{l}\text { Standard } \\
\text { deviation }\end{array}$ & Maximum & $p$ value \\
\hline Maximum & Indoor & 3595 & 4840 & 19,500 & $p<0.010$ \\
& Outdoor & 65 & 37 & 148 & \\
Minimum & Indoor & 36 & 10 & 57 & $p<0.001$ \\
& Outdoor & 28 & 5 & 41 & \\
Mean & Indoor & 110 & 80 & 345 & $p<0.001$ \\
& Outdoor & 39 & 15 & 74 & \\
\hline
\end{tabular}




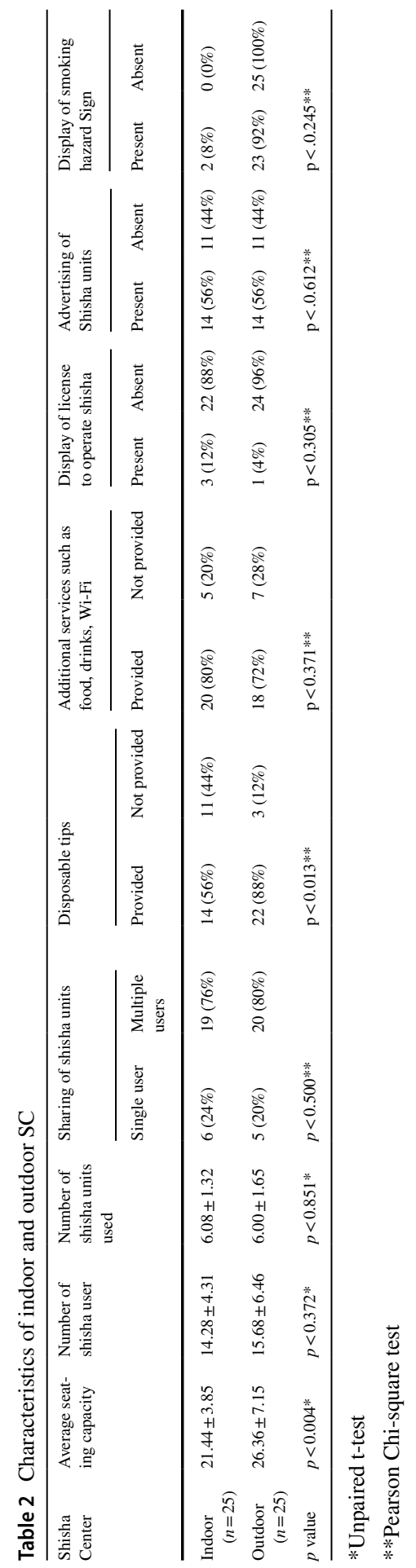

s. 
The significantly higher $\mathrm{PM}_{2.5}$ concentration in our study could be attributed to the greater number of shisha users during peak hours on weekends. Because the SC extended operating hours during weekends, students participated in much longer sessions than usual [25]. In our study, the mean $\mathrm{PM}_{2.5}$ concentration in outdoor SC was $65.12 \mu \mathrm{g} / \mathrm{m}^{3}$, the minimum and maximum were $27 \mu \mathrm{g} / \mathrm{m}^{3}$ and $148 \mu \mathrm{g} / \mathrm{m}^{3}$, respectively. This was slightly less than the study by Zhang BF et al. (2013) who recorded a mean value of $80.5 \mu \mathrm{g} / \mathrm{m}^{3}$ in outdoor SC [17]. Although the mean $\mathrm{PM}_{2.5}$ concentration in outdoor SC was substantially less than the indoor SC, it greatly exceeded the $24 \mathrm{~h}$ ambient air quality standards from the United States Environmental Protection Agency (EPA) $\left(35 \mu \mathrm{g} / \mathrm{m}^{3}\right)$ and the World Health Organization (WHO) $\left(25 \mu \mathrm{g} / \mathrm{m}^{3}\right)[20,26]$. The mean $\mathrm{PM}_{2.5}$ concentration in outdoor SC recorded in our study was $65.12 \mu \mathrm{g} / \mathrm{m}^{3}$, considered to be 'unhealthy'; the average $\mathrm{PM}_{2.5}$ concentration in indoor SC was considered to be 'hazardous' according to the United States EPA [20, 26].

We found that none of the SC in our study displayed the 'good' air quality and few centers had the worst air quality - 50 times greater than the maximum threshold for 'good' air quality according to United States EPA [27]. The 'hazardous' $\left(\geq 250 \mu \mathrm{g} / \mathrm{m}^{3}\right) \mathrm{PM}_{2.5}$ concentration is a serious health concern for children and adults. Hence, the SC close to the educational institutions has a high concentration of $\mathrm{PM}_{2.5}$, exposing its employees and bystanders [4, 6] to tobacco-specific carcinogens such as nicotine and 4-(methyl nitrosamino)-1-(3-pyridyl)-1-butanone. Shisha smokers also have an increased risk of lung cancer, oral cancer, bronchitis, cardiovascular disease, and low birth weight $[15,16,28]$.

Possible reasons for the clustering of SC around these educational facilities could include Malaysia's gradual development into an international education hub with the majority of the students coming from Middle Eastern, Central Asia, and Northern African countries. [4]. The use of shisha is a tradition and culturally familiar among these students [4]. Local peers of international students may also be drawn to these centers; thus, the trend of shisha usage is becoming common throughout the area. In addition, adolescents between the age group of 10-19 years studying in schools and Universities may also be attracted to this habit [29], though the sale of tobaccorelated products is banned in Malaysia for adolescents $[4,9,10]$.

The average seating capacity (21.44-26.3) and the number of shisha users (14.28-15.68) were slightly higher in outdoor than indoor SC; however, an equal number of shisha units (6.08-6.00) were used in both types of centers. A study by Gundavarapu et al. reported a total seating capacity from 20 to 132 (mean 58.3) with 6-68 (mean 15.2) shisha instruments [6]. The differences found pertain to seating density, size of the venues, seating capacity, and ventilation sources in indoor and outdoor SC. We observed high seating density with an equal number of shisha units in indoor SC thereby causing higher exposure of SHS. The display of a license to operate shisha (88-96\%) and smoking hazard signage (92-100\%) were absent from most SC. Gundavarapu et al. reported similar findings [6]. Most of the SC provided additional services such as food, drinks, and free Wi-Fi (80-72\%) that prompted young adults to practice longer sessions, and about 56\% of SC advertised shisha units and displayed promotion banners to attract the patrons. Kassem et al. reported similar observations [5]. 


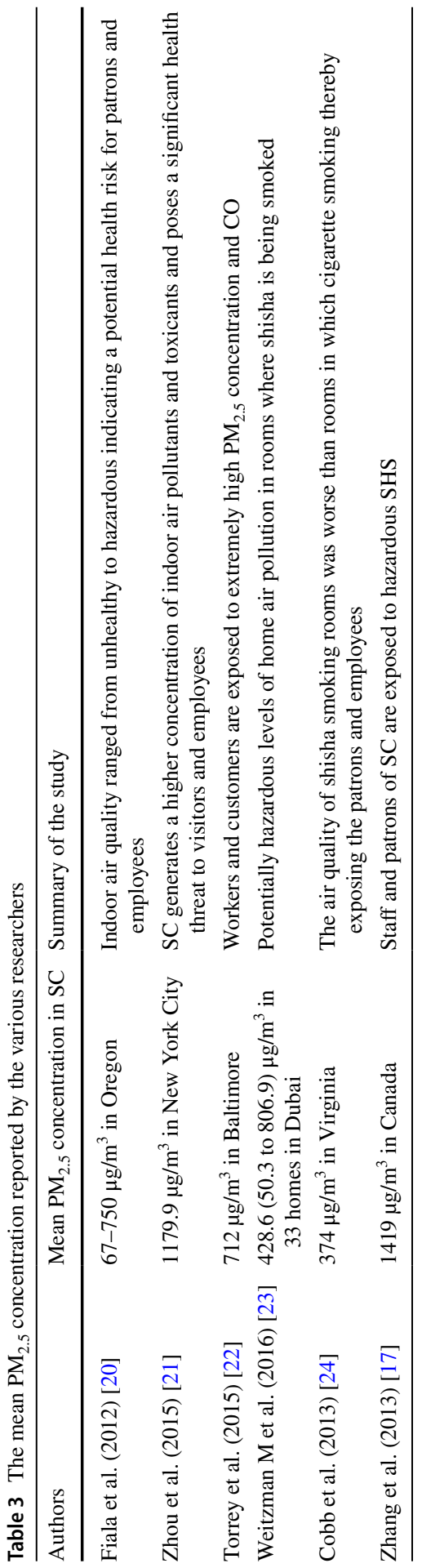

称 
We found that only $56 \%$ of indoor SC provided disposable mouthpieces in contrast to $88 \%$ of outdoor SC. Most of these patrons shared a single unit of shisha (76-80\%) in a group. This suggests that the young adults and students were not aware of the transmission of infectious diseases through saliva [30]. Although few SC provide individual disposable mouthpieces, certain pathogenic microorganisms such as Mycobacterium Tuberculosis may multiply and reside on the internal surface of the shisha pipe and water, and transmission of these pathogens may occur even with the use of disposable mouthpieces [4]. One study from the Middle East reported outbreaks of infectious diseases such as tuberculosis with the sharing of shisha smoking among groups [30]. Smokers are more susceptible to viral and bacterial respiratory infections as compared to nonsmokers [30]. The current COVID19 pandemic has posed significant health consequences and WHO has explicitly stated that smoking-induced lung disease, and the sharing of shisha and cigarettes, may significantly increase the susceptibility to SARS-CoV-2 infection and development of COVID-19 [31].

Limitations of our research include the measurements of $\mathrm{PM}_{2.5}$ concentration have been carried out during the peak hours on weekends, and no assessment of background air quality before the actual measurement. Hence, these results cannot be generalized to all days. SHS from SC with an attached kitchen that serves food may contribute to the additional exposure. These limitations need to be addressed in future prospective studies.

\section{Conclusion}

The results of our study show the high concentration of $\mathrm{PM}_{2.5}$ in indoor and outdoor SC at the perimeter of educational institutes can be hazardous and pose serious risks for the health of patrons, staff, bystanders, nonsmokers, and students residing in the vicinity. Public health advocates and policymakers need to strengthen tobacco guidelines and eliminate loopholes in the selling of alternate tobacco products. Furthermore, strict guidelines need to be framed regarding the online sale and marketing of shisha through social media and other websites. Most importantly, strict banning of additives to shisha needs to be considered. Efforts are needed to create awareness through university-based educational programs by community healthcare professionals for young adults on the harms associated with shisha usage.

Acknowledgements The study was supported by a grant from the Research Innovation and Management Centre (RIMC), SEGi University, Malaysia.

Author contributions SKV, SY, \& SSR were involved in designing of the study and collection of data. Rest of the authors were involved in drafting and final approval of the manuscript.

Funding The authors report no funding for this article. 


\section{Declarations}

Conflict of interest The authors declare no competing interests with regards to the authorship and/or publication of this article.

Ethical approval and patient consent The ethical clearance was obtained from the institutional ethical committee. All the patients involved in the study gave written consent for participation and publication of the research data.

\section{References}

1. Babaie J, Ahmadi A, Abdollahi G, Doshmangir L. Preventing and controlling water pipe smoking: a systematic review of management interventions. BMC Public Health. 2021;21(1):344.

2. Pratiti R, Mukherjee D. Epidemiology and adverse consequences of hookah/waterpipe use: a systematic review. Cardiovasc Hematol Agents Med Chem. 2019;17(2):82-93.

3. Lipkus IM, Eissenberg T, Schwartz-Bloom RD, Prokhorov AV, Levy J. Affecting perceptions of harm and addiction among college waterpipe tobacco smokers. Nicotine Tob Res. 2011;13(7):599-610.

4. Ramachandra SS, Yaldrum A. Shisha smoking: an emerging trend in Southeast Asian nations. J Public Health Policy. 2015;36(3):304-17.

5. Kassem NO, Jackson SR, Boman-Davis M, et al. Hookah smoking and facilitators/barriers to lounge use among students at a US University. Am J Health Behav. 2015;39(6):832-48.

6. Gundavarapu KC, Dicksit DD, Ramachandra SS. Characteristics of shisha smoking venues in a satellite township near Kuala Lumpur, Malaysia: an observational study. Tob Prev Cessat. 2016;2:70.

7. Jawad M, Charide R, Waziry R, Darzi A, Ballout RA, Akl EA. The prevalence and trends of waterpipe tobacco smoking: a systematic review. PLoS ONE. 2018;13(2):1-20.

8. Lee JJ, Wu Y, Wang MP, Yeung KC, Wong JY, Smith R. Waterpipe smoking among university students in Hong Kong: a cross-sectional study. BMC Public Health. 2020;20(1):543.

9. Al-Naggar RA, Al-Dubai SAR, Hamoud T, Al-Naggar RC, Al-Jashamy K. Prevalence and associated factors of smoking among Malaysian university students. Asian Pac J Cancer Prev. 2011;12:619-24.

10. Al-Naggar RA, Bobryshev YV. Shisha smoking and associated factors among medical students in Malaysia. Asian Pac J Cancer Prev. 2012;13:5627-32.

11. Waziry R, Jawad M, Ballout RA, Al Akel M, Akl EA. The effects of waterpipe tobacco smoking on health outcomes: an updated systematic review and meta-analysis. Int $\mathrm{J}$ Epidemiol. 2017;46(1):32-43.

12. Shihadeh A, Saleh R. Polycyclic aromatic hydrocarbons, carbon monoxide, "tar", and nicotine in the mainstream smoke aerosol of the narghile water pipe. Food Chem Toxicol. 2005;43:655-61.

13. Qasim H, Alarabi AB, Alzoubi KH, Karim ZA, Alshbool FZ, Khasawneh FT. The effects of hookah/waterpipe smoking on general health and the cardiovascular system. Environ Health Prev Med. 2019;24(1):58.

14. Bai A, Jin Y, Huang Y. Impact of secondhand smoke exposure on cognitive function among middle-aged and older women in China: findings from three waves of the China Health and Retirement Longitudinal Study. BMJ Open. 2020;10:e039824.

15. Cornacchione J, Wagoner KG, Wiseman KD, Kelley D, Noar SM, Smith MH, Sutfin EL. Adolescent and young adult perceptions of hookah and little cigars/cigarillos: implications for risk messages. J Health Commun. 2016;21(7):818-25.

16. Shearston J, Lee L, Eazor J, Meherally S, Park SH, Vilcassim MR, et al. Effects of exposure to direct and secondhand hookah and e-cigarette aerosols on ambient air quality and cardiopulmonary health in adults and children: protocol for a panel study. BMJ Open. 2019;9:e029490.

17. Zhang B, Haji F, Kaufman P, Muir S, Ferrence R. "Enter at your own risk": a multimethod study of air quality and biological measures in Canadian waterpipe cafes. Tob Control. 2015;24(2):175-81. 
18. Kim KH, Kabir E, Jahan SA. Waterpipe tobacco smoking and its human health impacts. J Hazard Mater. 2016;317:229-36.

19. Salloum RG, Maziak W, Hammond D, Nakkash R, Islam F, Cheng X, et al. Eliciting preferences for waterpipe tobacco smoking using a discrete choice experiment: implications for product regulation. BMJ Open. 2015;5(9):009497.

20. Fiala SC, Morris DS, Pawlak RL. Measuring indoor air quality of hookah lounges. Am J Public Health. 2012;102(11):204.

21. Zhou S, Weitzman M, Vilcassim R, Wilson J, Legrand N, Saunders E, et al. Air quality in New York city hookah bars. Tob Control. 2015;24(e3):193-8.

22. Torrey CM, Moon KA, Williams DA, Green T, Cohen JE, Navas-Acien A, et al. Waterpipe cafes in Baltimore, Maryland: carbon monoxide, particulate matter, and nicotine exposure. J Expo Sci Environ Epidemiol. 2015;25(4):405-10.

23. Weitzman M, Yusufali AH, Bali F, Vilcassim MJR, Gandhi S, Peltier R, et al. Effects of hookah smoking on indoor air quality in homes. Tob Control. 2016;26(5):586-91.

24. Cobb CO, Vansickel AR, Blank MD, Jentink K, Travers MJ, Eissenberg T. Indoor air quality in Virginia waterpipe cafes. Tob Control. 2013;22:338-43.

25. Majeed BA, Sterling KL, Weaver SR, Pechacek TF, Eriksen MP. Prevalence and harm perceptions of hookah smoking among U.S. adults, 2014-2015. Addict Behav. 2017;69:78-86.

26. Revised air quality standards for particle pollution and updates to the Air Quality Index (AQI). http://www.epa.gov/airquality/particlepollution/actions.html Accessed June 3, 2020.

27. Zhou S, Behrooz L, Weitzman M, Pan G, Vilcassim R, Mirowsky JE, et al. Secondhand hookah smoke: an occupational hazard for hookah bar employees. Tob Control. 2017;26(1):40-5.

28. Masjedi MR, Taghizadeh F, Hamzehali S. Air pollutants associated with smoking in indoor/outdoor of waterpipe cafés in Tehran, Iran: concentrations, affecting factors and health risk assessment. Sci Rep. 2019;9:3110.

29. Othman M, Aghamohammadi N, Nik Farid ND. Determinants of shisha use among secondary school students in Sudan. BMC Public Health. 2019;19(1):1390.

30. Lawrence H, Hunter A, Murray R, Lim WS, McKeever T. Cigarette smoking and the occurrence of influenza-systematic review. J Infect. 2019;79(5):401-6.

31. Grundy EJ, Suddek T, Filippidis FT, Majeed A, Coronini-Cronberg S. Smoking, SARS-CoV-2 and COVID-19: a review of reviews considering implications for public health policy and practice. Tob Induc Dis. 2020;18:58.

Publisher's Note Springer Nature remains neutral with regard to jurisdictional claims in published maps and institutional affiliations.

Suresh Kandagal Veerabhdrappa, MDS, is a Senior Lecturer at the Department of Oral Diagnostic Sciences, Faculty of Dentistry, SEGi University, Malaysia.

Seema Yadav, MDS, is a Lecturer at the Department of Periodontology and implantology, Faculty of Dentistry, SEGi University, Malaysia.

Srinivas Sulugodu Ramachandra, MDS is a PhD student at Ivanovski Tissue Engineering and Additive Manufacturing group(iTEAM), School of Dentistry at the University of Queensland, Australia.

Daniel Devaprakash Dicksit, MPH, is a Senior Lecturer at the Department of Public Health Dentistry, Faculty of Dentistry, SEGi University, Malaysia.

Khairiyah Bt Abd Muttalib, DPHDent, is a former Dean at Faculty of Dentistry, SEGi University, Malaysia.

Ahmad Termizi Bin Zamzuri, MSc. DPH, DDPHRCS, PGCert.MedEd, is a Dean at Faculty of Dentistry, SEGi University, Malaysia. 


\section{Authors and Affiliations}

Suresh Kandagal Veerabhdrappa ${ }^{1}$ (D) Seema Yadav ${ }^{1}$.

Srinivas Sulugodu Ramachandra ${ }^{2}$ - Daniel Devaprakash Dicksit ${ }^{1}$.

Khairiyah Bt Abd Muttalib ${ }^{1}$ - Ahmad Termizi Bin Zamzuri ${ }^{1}$

Srinivas Sulugodu Ramachandra

s.sulugoduramachandra@uq.edu.au

Daniel Devaprakash Dicksit

daniel@segi.edu.my

Khairiyah Bt Abd Muttalib

kaymuttalib@segi.edu.my

Ahmad Termizi Bin Zamzuri

termizizamzuri@segi.edu.my

1 Faculty of Dentistry, SEGi University, No. 9 Jalan Teknologi, Taman Sains, Petaling Jaya, 47810 Kota Damansara, Selangor, Malaysia

2 Ivanovski Tissue Engineering and Additive Manufacturing Group (iTEAM), School of Dentistry, The University of Queensland, Oral Health Centre Herston, 288 Herston Rd, Herston, QLD 4006, Australia 